\title{
Comparison of Effect of Anterior Colporrhaphy and Transobturator Tape Surgeries on Urinary Incontinence and Sexual Performance in Women
}

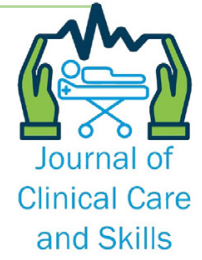

and Skills

\section{ARTICLE INFO}

\section{Article Type}

Original Research

\section{Authors}

Mahmoudi F. ${ }^{* 1} M S C$,

Ghaffari P. ${ }^{2} M D$,

Hosseinpour R. ${ }^{3} M D$

How to cite this article
Mahmoudi F, Ghaffari P,
Hosseinpour R. Comparison of Ef-
fect of Anterior Colporrhaphy and
Transobturator Tape Surgeries on
Urinary Incontinence and Sexual
Performance in Women. Journal of
Clinical Care and Skills.
2020;1(4):175-180.

${ }^{1}$ Midwifery Department, Medicine Faculty, Yasuj University of Medical Sciences, Yasuj, Iran

2"Obstetrics \& Gynecology Department, Medicine Faculty" and "Social Determinants of Health Research Center", Yasuj University of Medical Sciences, Yasuj, Iran ${ }^{3}$ Surgical Department, Medicine Faculty, Yasuj University of Medical Sciences, Yasuj, Iran

\section{*Correspondence}

Address: Medicine Faculty, Yasuj University of Medical Sciences, Shahid Ghorbanali Jalil Street, Yasuj, Iran. Postal Code: 7541994579.

Phone: +98 (74) 33220164

Fax: +98 (74) 33235144

fatemeh.mahmoodii66@yahoo.com

\section{Article History}

Received: September 01, 2019

Accepted: January 06, 2020

ePublished: October 01, 2020

\section{A B S T R A C T}

Aims Pelvic floor disorders such as urinary incontinence and pelvic and genital prolapse affect sexual function and quality of life. The aim of the present study was to compare the effect of anterior colporrhaphy and transobturator tape (TOT) surgeries on urinary incontinence and sexual function in women.

Materials \& Methods This retrospective cohort clinical trial study was performed on 136 women with pelvic prolapse and urinary incontinence who referred to Shahid Mofatteh Women's Clinic in Yasuj, Iran, from 2016 to 2018. All patients in the two groups of 68 underwent anterior colporrhaphy and TOT surgeries. Non-random sampling method was performed. Data were collected by Pelvic Organ Prolapse Incontinence Sexual Questionnaire (PISQ) and Female Sexual Function Index (FSFI) before and 6 months after surgery, and analyzed using SPSS 20 software through Chi-square test, independent t-test and paired t-test.

Findings $77.9 \%$ of women had urinary incontinence or leakage during sneezing, coughing, or sexual intercourse, which improved by $95.6 \%$ after surgery. The variables of the PISQ questionnaire were significantly different in terms of behavior and emotions and physical factors, before and after TOT and anterior colporrhaphy surgeries $(\mathrm{p}<0.05)$. The average total score of women's sexual function before and after surgery did not show a significant difference $(\mathrm{p}>0.05)$. In the TOT surgery group, a significant increase was observed in the areas of sexual desire, sexual arousal, orgasm, and sexual satisfaction after surgery.

Conclusion TOT and anterior colporrhaphy surgeries are effective in relieving urinary incontinence, but TOT surgery is more effective in the long term.

Keywords Anterior Colporrhaphy; Trans-obturator Tape; Urinary Incontinence; Sexual Behavior; Sexual Satisfaction

\section{I T A T I O N L I N K S}

[1] Health assessment: a nursing ... [2] Defining sexual health: a descriptive ... [3] Textbook of sexual ... [4] Sexual dysfunctions and associated factors in women ... [5] Female sexual dysfunction in a healthy Austrian ... [6] Sexual dysfunctions in urban china: A population ... [7] Prevalence and risk factors for low sexual function ... [8] Study on the effect of colporrhaphy on women's ... [9] Sexual function in women with genital prolapse ... [10] The Relationship between body mass index ... [11] Effect of pelvic organ prolapses surgery (POP) ... [12] Female sexual function after modified pelvic floor ... [13] The relationship between self-esteem and sexual ... [14] Urinary incontinence: prevalence, risk factors, ... [15] Prevalence of urinary incontinence among ... [16] Prevalence, incidence and remission of urinary incontinence ... [17] Prevalence of urinary incontinence in men, women ... [18] Transobturator tape in treatment of stress urinary ... [19] Evaluation of long-term results of tension-free ... [20] Tension-free midurethral slings in the treatment ... [21] Mobys dictionary of medicine, nursing and health ... [22] The female sexual function index (FSFI) ... [23] Pelvic organ Prolapse/Urinary Incontinence sexual ... [24] Development and validation of a new screening ... [25] The effects of stress incontinence surgery on ... [26] The impact of stress incontinence surgery on ... [27] Sexual function after vaginal surgery for pelvic organ ... [28] Sexual function in women after surgery for ... [29] Female sexual funection and pelvic floor ... [30] Evaluating the effects of colporrhaphy on the ... [31] Female sexual function evaluation of the tension ... [32] Factors associated with sexual dysfunction in ... [33] A short form of the pelvic organ prolapse/Urinary ... [34] Assessment of sexual function in women with pelvic ... 


\section{Comparison of Effect of Anterior Colporrhaphy and ...}

Sexual desire, which is the source of different changes in human life, can be disrupted by several factors. Against sexual desire, we should be realistic and it cannot be ignored, because, like other human instinctual desires, it has existed since the birth of the child and has grown, evolved, and flourished accordingly [1]. The World Health Organization defines sexual health as the integration and harmony among mind, feeling, and body that leads the social and intellectual aspects of an individual to promote his personality resulting in communication and love. Therefore, any disorder causing an inconsistency, and consequently dissatisfaction with a sexual relationship can lead to sexual dysfunction [2]. According to global statistics, the prevalence of natural sexual dysfunction is about $41 \%{ }^{[3,4]}$, whereas the prevalence of sexual dysfunction is reported to be $22 \%$ in Australia, 29.5\% in Turkey, and 35\% in China [5-7]. Studies have shown that these disorders affect the quality of life in people and evaluating sexual function plays an important role in studies associated with quality of life [8-10].

Sexual dysfunction is a common problem that is more common in women. It has also been observed in some studies that pelvic floor disorders, such as urinary incontinence and pelvic organ prolapse or genital prolapse affect sexual function [10,11]. Bastani et al. [12] and Ramezani et al. [13] reported the prevalence of sexual dysfunction in Iran as $39.5 \%$ and $64.5 \%$, respectively. According to global studies, the prevalence of this disorder has been reported vary, as a total prevalence of urinary incontinence in Jeddah, Riyadh, and Norway was $41.41 \%, 29 \%$, and $18.7 \%$, respectively [14-16]. Urinary incontinence can affect all age groups of women with a prevalence of $45-25 \%$ [17].

Urinary incontinence is one of the factors that affect sexual function, which can cause leakage of urine or urinary incontinence during intercourse leading to feelings of shame and guilt in the woman.

Stress urinary incontinence (involuntary leakage of urine) is the most common type of urinary incontinence in women with a prevalence of 5-20\%, which adversely affects social, psychological, family, and sexual life, as well as quality of life of women [1820]. It limits women's physical activity and impairs their personal hygiene, and ultimately leads to avoidance of sexual intercourse [19, 21].

Currently, there is no available and accepted drug to treat these women. Drugs, such as estrogens, alphaadrenergic receptor agonists, beta-adrenergic receptor agonists, and tricyclic antidepressants are used to treat stress urinary incontinence. However, they are less likely to be effective and it can be treated with surgery.

All surgical procedures are based on the correction of the urethrovesical angle in order to prevent urethral descent during the increase of intra-abdominal pressure and provide support for the urethra during increased pressure [19, 20]. To solve this problem, surgeries to place a sling under the urethra, including classic pubovaginal sling using autologous sling materials (such as rectus fascia and fascia lata), which is anterior colporrhaphy, as well as and tension-free vaginal tape (TVT) and transobturator tape (TOT) are performed. Therefore, the aim of this study was to compare the effect of anterior colporrhaphy and TOT surgeries on urinary incontinence and sexual function in women.

\section{Materials and Methods}

This retrospective cohort study was performed on 136 women who volunteered for anterior colporrhaphy and TOT surgeries diagnosed with stress urinary incontinence and pelvic organ prolapse, who referred to the Shahid Mofatteh Clinic, Yasuj in 2016-2018. Using nonrandom convenience sampling and through the interview and completing the questionnaire before and 6 months after the surgery the samples were selected. Using relevant research, the required number of samples was estimated at 68 people in each group, with 95\% confidence level and $80 \%$ test power. The subjects were divided into two groups of 68 cases; the first group was volunteered for anterior colporrhaphy surgery and the second group volunteered for TOT surgery. Inclusion criteria were consent to participate in the study, symptoms of urinary stress incontinence, sexual activity, genital prolapse diagnosed by a physician, reading and writing literacy, being married with children, Iranian nationality, being at first marriage, and single marriage. Exclusion criteria included being divorced, last delivery at least 12 months ago, history of pelvic and breast surgery, history of narcotic drugs or antidepressants in the patient or spouse, history of chronic illness, diabetes, hypertension, and heart disease in the patient or spouse, sexual problems in the spouse (premature ejaculation and impotence), and experiencing severe stressful events in one of the couples over the past 6 months. The eligible subjects for the study were selected, and the groups were matched in terms of the first marriage, the number of children, and the type of delivery.

After obtaining the approval by the Ethics Committee of Yasuj University of Medical Sciences (IR.YUMS.REC.1396.170) and the official introduction, the researcher referred to the gynecology department of Imam Sajjad Hospital for sample collecting before surgery. After surgery, through making phone calls or referring to the clinic, while obtaining the subjects' consent, interviewed with the samples and completed the questionnaires. In the anterior colporrhaphy method, after anesthesia and placing the patient in the lithotomy position, an incision was made in the anterior wall of the vagina from the vicinity of the bladder neck to the vaginal arch, and the vaginal epithelium was completely separated from the endopelvic fascia. Then, the endopelvic fascia on both sides was closed 
and repaired with 2-0 Vicryl suture using the intermittent technique. The vaginal mucosa was then brought closer together with 0 chromic suture and repaired continuously. In cases with urinary incontinence, Kelly suture, used in endopelvic fascia under the bladder sphincter, is used to angle the urethra.

In the TOT method, after anesthesia, the patient is first placed in a lithotomy position, and then the tunneler is identified from the point of intersection of the line that intersects the femoral line $1 \mathrm{~cm}$ above the clitoris. On the other hand, by making a $2 \mathrm{~cm}$ incision in the vaginal mucosa in the sub-urethral area, the para-urethral space was opened from the vagina and the finger was directed to the back of the symphysis pubis. After making sure to enter the obturator space, using a tunneler we placed the TOT from the outside to the inside from the identified point, and then the vaginal mucosa was repaired. The foley catheter was inserted for 24 hours.

The Pelvic Organ Prolapse Incontinence Sexual Questionnaire (PISQ) with 12 questions includes three main dimensions of behavior and excitement (4 questions), physical factors, such as incontinence or leakage of urine during intercourse, feelings of fear, feelings of shame and guilt and lack of comfort in the bedroom (5 questions), and sexual partner-related factors ( 3 questions). PISQ is scored 0-5 on the Likert scale by "never", "rarely", "sometimes", "usually" and "always". Also, the validity and reliability of the PISQ are 0.84 and 0.86 using Cronbach's alpha coefficient [22].

The Female Sexual Function Index (FSFI) includes 19 questions assessing the dimensions of libido, excitement, lubrication, orgasm, sexual satisfaction, and pain. The questions are scored 0-5 and the highest score is 36 . This questionnaire has been widely used in several studies and its validity and reliability have been proven. FSFI is a standard general questionnaire and its reliability and validity have been confirmed by Mohammadi et al. and also Momeni Movahed et al. have reported a Cronbach's alpha coefficient of 0.73 for approving its reliability and validity for Iranian and Arab women [22-24].

Data analysis was performed using SPSS 20 statistical software and descriptive and analytical statistical methods. The values were expressed by average, standard deviation, and frequency distribution. Data analysis was done using the Chi-squared test, independent t-test, and paired t-test.

\section{Findings}

The average age of women was $44.5 \pm 37.1$ years (ranged 25-77 years) and the average duration of their marriage was $18.70 \pm 5.10$ years. In the colporrhaphy and TOT groups, $60.3 \%$ and $79.4 \%$ of the cases were housewives, $51.5 \%$ and $60.3 \%$ had secondary and high school education, and $62.4 \%$ and 81.2\% were living in urban areas, respectively. 77.9\% of women had urinary incontinence or leakage of urine during sneezing, coughing, or intercourse, and $41.9 \%$ had fear of urinary incontinence or leakage of urine during intercourse that after surgery, $95.6 \%$ of them recovered. The studied groups did not have significant statistical differences in terms of quantitative and qualitative demographic variables (Table 1).

Table 1) Comparison of the quantitative (mean) and qualitative (absolute and relative frequency) demographic variables in the two studied groups ( $\mathrm{n}=68$ per group; numbers in parentheses are percent)

\begin{tabular}{lccc}
\hline \multicolumn{1}{c}{ Variables } & $\begin{array}{c}\text { Anterior } \\
\text { Colporrhaphy } \\
\text { group }\end{array}$ & TOT group & P. value \\
\hline Quantitative variables & $44.30 \pm 37.10$ & $45.02 \pm 34.20$ & 0.78 \\
$\begin{array}{l}\text { Age (year) } \\
\text { Number of deliveries }\end{array}$ & $2.93 \pm 1.21$ & $2.78 \pm 1.32$ & 0.89 \\
$\begin{array}{l}\text { Duration of marriage } \\
\text { (years) }\end{array}$ & $19.20 \pm 7.20$ & $18.50 \pm 3.20$ & 0.84 \\
$\begin{array}{l}\text { BMI (kg/m }{ }^{2} \text { ) } \\
\text { Qualitative variables }\end{array}$ & $31.57 \pm 2.44$ & $30.63 \pm 7.66$ & 0.73 \\
Education level & $19(27.9)$ & $15(22.1)$ & \\
$\begin{array}{l}\text { Elementary } \\
\text { Secondary and high } \\
\text { school }\end{array}$ & $35(51.5)$ & $41(60.3)$ & 0.91 \\
$\begin{array}{l}\text { Diploma and above } \\
\text { Occupational status }\end{array}$ & $14(20.6)$ & $12(17.6)$ & \\
$\begin{array}{l}\text { Employed } \\
\text { Housewife }\end{array}$ & $27(39.7)$ & $14(20.6)$ & 0.1 \\
$\begin{array}{l}\text { Type of delivery } \\
\text { Vaginal }\end{array}$ & $41(60.3)$ & $54(79.4)$ & \\
Cesarean & $38(55.8)$ & $42(61.7)$ & 0.64 \\
\hline
\end{tabular}

The variables of the PISQ questionnaire showed statistically significant differences in terms of behavior and emotions and in terms of physical factors, before and after TOT and anterior colporrhaphy surgeries (Table 2).

Table 2) Comparison of the mean of pelvic organ prolapse incontinence sexual questionnaire (PISQ) variables in the two groups of transobturator tape (TOT) and anterior colporrhaphy surgeries before and 6 months after surgery

\begin{tabular}{|c|c|c|c|}
\hline Variables & $\begin{array}{c}\text { Anterior } \\
\text { Colporrhaphy group }\end{array}$ & $\begin{array}{c}\text { TOT } \\
\text { group }\end{array}$ & P. value \\
\hline \multicolumn{4}{|c|}{ Behavior and emotions } \\
\hline Before surgery & $7.81 \pm 1.80$ & \multirow{2}{*}{$\begin{array}{c}9.25 \pm 2.20 \\
11.42 \pm 1.1 \\
0\end{array}$} & \multirow[b]{2}{*}{$<0.001$} \\
\hline After surgery & $11.21 \pm 1.20$ & & \\
\hline \multicolumn{4}{|l|}{ Physical factor } \\
\hline Before surgery & $14.62 \pm 1.09$ & $\begin{array}{c}13.94 \pm 2.0 \\
3\end{array}$ & \multirow{2}{*}{$<0.05$} \\
\hline After surgery & $16.90 \pm 0.90$ & $\begin{array}{c}15.75 \pm 1.7 \\
0\end{array}$ & \\
\hline \multicolumn{4}{|c|}{ Factors related to sex partner } \\
\hline $\begin{array}{l}\text { Before surgery } \\
\text { After surgery }\end{array}$ & $\begin{array}{r}5.11 \pm 1.60 \\
6.80 \pm 1.30\end{array}$ & $\begin{array}{l}4.82 \pm 1.25 \\
6.50 \pm 0.50\end{array}$ & 0.1 \\
\hline \multicolumn{4}{|l|}{ Total score } \\
\hline Before surgery & $27.54 \pm 4.20$ & $\begin{array}{c}28.01 \pm 4.0 \\
4\end{array}$ & \multirow{2}{*}{$<0.05$} \\
\hline After surgery & $34.91 \pm 4.81$ & $\begin{array}{c}33.49 \pm 5.1 \\
0\end{array}$ & \\
\hline
\end{tabular}

The mean total score of sexual function before and after TOT and anterior colporrhaphy surgeries did not show a statistically significant difference ( $p>0.05)$. The mean scores of the FSFI variables in the 
Comparison of Effect of Anterior Colporrhaphy and ...

TOT surgery group increased significantly in terms of dimensions of sexual desire, sexual arousal, orgasm, and sexual satisfaction after the surgery compared to before surgery. However, there was no significant difference in other dimensions. The mean scores of the FSFI variables in the anterior colporrhaphy surgery group did not change significantly after surgery than before surgery (Table 3).

Table 3) Comparison of the mean scores of female sexual function index (FSFI) variables in the two groups of transobturator tape (TOT) and anterior colporrhaphy surgeries before and 6 months after surgery

\begin{tabular}{|c|c|c|}
\hline Variables & $\begin{array}{c}\text { Anterior } \\
\text { Colporrhaphy group }\end{array}$ & TOT group \\
\hline \multicolumn{3}{|l|}{ Sexual desire } \\
\hline Before surgery & $3.81 \pm 1.30$ & $3.72 \pm 1.70$ \\
\hline After surgery & $3.54 \pm 1.12$ & $3.97 \pm 1.20$ \\
\hline P. value & 0.20 & 0.01 \\
\hline \multicolumn{3}{|l|}{ Sexual arousal } \\
\hline Before surgery & $3.94 \pm 1.20$ & $3.84 \pm 0.90$ \\
\hline After surgery & $4.05 \pm 1.32$ & $4.01 \pm 1.10$ \\
\hline P. value & 0.2 & 0.025 \\
\hline \multicolumn{3}{|c|}{ Vaginal moisturizing } \\
\hline Before surgery & $4.20 \pm 1.36$ & $4.02 \pm 1.45$ \\
\hline After surgery & $4.50 \pm 1.21$ & $4.00 \pm 1.30$ \\
\hline P. value & 0.10 & 0.2 \\
\hline \multicolumn{3}{|l|}{ Orgasm } \\
\hline Before surgery & $3.90 \pm 1.52$ & $3.70 \pm 1.15$ \\
\hline After surgery & $4.00 \pm 1.38$ & $3.91 \pm 1.10$ \\
\hline P. value & 0.29 & 0.01 \\
\hline \multicolumn{3}{|c|}{ Sexual satisfaction } \\
\hline Before surgery & $3.75 \pm 1.30$ & $3.91 \pm 1.12$ \\
\hline After surgery & $4.01 \pm 1.20$ & $4.20 \pm 1.30$ \\
\hline P. value & 0.30 & 0.001 \\
\hline \multicolumn{3}{|l|}{ Pain } \\
\hline Before surgery & $4.10 \pm 1.20$ & $3.96 \pm 1.40$ \\
\hline After surgery & $3.89 \pm 0.90$ & $3.88 \pm 1.10$ \\
\hline P. value & 0.9 & 0.07 \\
\hline \multicolumn{3}{|c|}{ Total score of sexual function } \\
\hline Before surgery & $24.16 \pm 5.20$ & $23.15 \pm 5.91$ \\
\hline After surgery & $23.47 \pm 6.21$ & $23.97 \pm 5.41$ \\
\hline P. value & 0.06 & 0.2 \\
\hline
\end{tabular}

\section{Discussion}

The mean overall score of women's sexual function before and after TOT and anterior colporrhaphy surgeries did not show a statistically significant difference, but there was a relative improvement in sexual function. Jafarnejad et al. studied 50 women who underwent surgery, and the score of sexual function in the dimensions of desire, arousal, and orgasm did not show a significant difference [8]. In Tuncer et al. study in 2016 in the United States on 49 women who underwent TOT surgery, the cases did not show a statistically significant difference in sexual function, but sexual desire and quality of life improved [25]. Brubaker et al. concluded that overall sexual function improves after successful surgery [26]. Pauls et al. showed that sexual function do not change after surgery [27], which is consistent with the results of the present study. Azar et al. after a 3-month follow-up reported that the score of women's sexual function increased from 15.09 to 21.9 following a colporrhaphy surgery ${ }^{[28]}$ that the difference in the results can be due to the difference in the number of samples and the time after the surgery.

The present study showed that dyspareunia, vaginal dryness during intercourse, lack of comfort after intercourse, and pelvic pain after intercourse decreased in women after anterior colporrhaphy and TOT surgeries. Handa et al. reported that stress urinary incontinence in women is associated with decreased libido, vaginal dryness, and dyspareunia, and treatment of this disorder has a positive effect on these complications [29]. Kariman et al. also showed that after colporrhaphy surgery, dyspareunia, queefing, vaginal dryness during intercourse, headache after intercourse, and urinary incontinence during orgasm decreased in women [30]. Bastani et al. showed that after pelvic organ prolapse surgery, urinary incontinence rate, fear of urinary incontinence, and prolapse significantly reduced within 3 months after surgery. They also reported that postoperative pain was significantly reduced in $63.4 \%$ of patients after surgery [12], which can be due to the lack of removal of vaginal mucus in the surgery, which is consistent with the results of the present study. However, a study by Jafarnejad et al. in 2013 on 50 women showed that $46 \%$ of the samples complained of vaginal dryness and $32 \%$ of painful intercourse [8], which was not consistent with the present study. The reason for this difference may be the duration of the study (three-month follow up), whereas the cases in this research were followed up for 6 months after surgery.

In the present study, $77.9 \%$ of women had urinary incontinence or leakage of urine during sneezing, coughing, or intercourse, which improved by $95.6 \%$ after surgery. In a study by Pace et al., $67 \%$ of women experienced urinating or leakage during intercourse, $96 \%$ during orgasm, and $4 \%$ at orgasm, of whom $97.1 \%$ reported no urinary incontinence after TOT surgery, $90.1 \%$ reported relative improvement in their sex lives, and $9.9 \%$ had a poor sexual function after surgery [31], which is consistent with the present study.

In the present study, $19 \%$ of the subjects reported lack of security in the bedroom, 29.1\% reported fear of their children waking up at night, and $42 \%$ fear of complications during intercourse (urinary incontinence or urinary leakage during sexual pleasure) as factors affecting sexual dysfunction, which following surgery, urinary incontinence showed a significant reduction, which is consistent with Abu Ali et al. study. In this study, 23\% of cases announced the lack of a toilet in the bedroom, 24\% reported lack of security in the bedroom, and 36\% announced fear of their children waking up at night [32].

According to the results, sexual satisfaction improved 6 months after TOT surgery. In a study by Rogers et al., 3 and 6 months after surgery, sexual satisfaction (based on PISQ) was reduced [33]. The present study 
showed that sexual satisfaction increased according to PISQ in terms of physical and emotionalbehavioral factors. Tuncer et al. study showed that TOT surgery was more successful in treating urinary incontinence than other surgeries. Therefore, sexual desire in these patients improved and the quality of life in the TOT surgery group was higher [25]. Momeni Movahed et al. reported that women who underwent TOT surgery showed significant differences regarding emotional tendencies and physical factors (urinary incontinence or leakage of urine during intercourse, feelings of fear, feelings of shame and guilt, and discomfort in the bedroom) [23], which is consistent with the present study. Kammerer et al. study on women's sexual satisfaction with pelvic floor problems reported better performance in women in physical factors and partner-related factors; however, no difference was observed in the orgasm, excitement, and erection of the studied women [34], which is consistent with the present study. However, it is inconsistent with the research of Jafarnejad et al. who showed that colporrhaphy surgery did not affect sexual satisfaction ${ }^{[8]}$, which can be due to the type of surgery.

According to the results of this study, colporrhaphy and TOT surgeries were effective in relieving urinary incontinence and corrected anatomy, and the patients did not suffer from urinary incontinence or leakage of urine during intercourse and did not feel ashamed or guilty, but in terms of long-term outcomes, TOT surgery showed better results. Women's sexual function is multifactorial, and anatomical correction alone cannot significantly affect the aspects of sexual function, such as orgasm, sexual desire, sexual problems of the spouse, satisfaction, etc.

One of the limitations of the study was difficulty in expressing sexual dysfunction by patients due to moral constraints, and also their spouses were not visited.

It is suggested to assess sexual satisfaction and improvement of urinary incontinence over longer periods (one year) in women candidates for colporrhaphy and TOT surgeries.

\section{Conclusion}

Colporrhaphy and TOT surgeries are effective in relieving urinary incontinence and anatomical correction; however, in terms of long-term outcomes, TOT surgery showed better results and improved sexual function and satisfaction.

Acknowledgments: We would like to thank the ViceChancellor for Research of the University of Medical Sciences, the staff of Imam Sajjad Hospital, and the Yasuj Women's Clinic, who helped and guided us in all stages of conducting this research.

Ethical Permission: This research was approved by the Ethics Committee of Yasuj University of Medical Sciences (IR.YUMS.REC.1396.170).
Conflict of interest: There is no conflict of interest.

Authors' Contribution: Mahmoudi F. (First author), Introduction author/ Original researcher/ Statistical analyst/ Discussion author (50\%); Ghaffari P. (Second author), Methodologist/ Assistant (30\%); Hosseinpour R. (Third author), Introduction author/ Assistant (20\%)

Funding: The Vice-Chancellor for Research and Technology of Yasuj University of Medical Sciences funded this research.

\section{References}

1- Fuller J, Schaller-Ayers J. Health assessment: a nursing approach. $3^{\text {rd }}$ Edition. Philadelphia: Lippincott Williams \& Wilkins; 2000. p.593-6.

2- Edwards WM, Coleman E. Defining sexual health: a descriptive overview. Arch Sex Behav. 2004;33(3):189-95. 3- Jahanfar S, Molaeinezhad M. Textbook of sexual disorders. $3^{\text {rd }}$ Edition. Tehran: Beezhe and Salemi Publication; 2007. [Persian]

4- Bahrami N, Alizadeh S, Bahrami S. Sexual dysfunctions and associated factors in women of Reproductive age .J Shahid Beheshti Nurs Midwifery Fac. 2011;21(75):8-13. [Persian]

5- Ponholzer A, Roehlich M, Racz U, Temml C, Madersbacher S. Female sexual dysfunction in a healthy Austrian cohort: prevalence and risk factors. Eur Urol. 2005:47(3):366-74.

6- Parish WL, Laumann EO, Pan S, Hao Y. Sexual dysfunctions in urban china: A population-based national survey of men and women. J Sex Med. 2007;4(6):1559-74. 7- Aslan E, Beji NK, Gungor I, Kadioglu A, Dikencik BK. Prevalence and risk factors for low sexual function in women: a study of 1,009 women in an outpatient clinic of a university hospital in Istanbul. J Sex Med. 2008;5(9):204452.

8- Jafarnejad F, Kazemeini B, Mazloum SR, Emami Moghadam Z, Sefidgran A. Study on the effect of colporrhaphy on women's sexual function and satisfaction. Iran J Obstet Gynecol Infertil. 2013;16(59):14-23. [Persian] 9- Goodarzi F, Rad P, Hekmatzadeh F, Aramesh S. Sexual function in women with genital prolapse before and after Anterior posterior Colporrhaphy (APR). Iran J Obstet Gynecol Infertil. 2016;19(34):1-9. [Persian]

10- Faridi H, Najar S, Javadnoori M. The Relationship between body mass index and women sexual function. Iran J Obstet Gynecol Infertil. 2013;16(74):20-8. [Persian]

11- Kamranpour SB, Oudi M, Dibaj SS, Alizadeh S, Azin SA. Effect of pelvic organ prolapses surgery (POP) on sexual function. J knowledge Health. 2013;8(3):99-104. [Persian] 12- Bastani P, Hajebrahimi S, Hamedani R, Oskuei AP. Female sexual function after modified pelvic floor organ prolapse repair. Med J Tabriz Univ Med Sci Health Ser. 2012;34(1):13-6. [Persian]

13- Ramezani N, Dolatian M, Shams J, Alavi H. The relationship between self-esteem and sexual dysfunction and satisfactoion in women. J Arak Med Univ. 2012;14(6):57-65. [Persian]

14- Altaweel W, Alharbi M. Urinary incontinence: prevalence, risk factors, and impact on health related quality of life in Saudi women. Neurourol Urodyn. 2012;31(5):642-5.

15- Al-badr A, Brasha H, Al-raddadi R, Noorwali F, Ross S. Prevalence of urinary incontinence among saudi women. Int J Gynaecol Obstet. 2012;117(2):160-3.

16- Ebbesen MH, Hunskaar S, Rortveit G, Hannestad YS. Prevalence, incidence and remission of urinary 
Comparison of Effect of Anterior Colporrhaphy and ...

incontinence in women; longitudinal data from the Norwegian HUNT study. BMC Urol. 2013;13:27.

17- Buckley BS, Lapitan MC. Prevalence of urinary incontinence in men, women, and children--current evidence: findings of the fourth international consultation on incontinence. Urology. 2010;76(2):265-70.

18- Magon N, Chopra SV. Transobturator tape in treatment of stress urinary incontinence: it is time for a new gold standard. N Am J Med Sci. 2012;4(5):226-30.

19- Keshvari M, Darabi MR, Abbasioun R. Evaluation of long-term results of tension-free vaginal tape in the management of stress urinary incontinence in women: 6 years follow up. Iran J Obstet Gynecol Infertil. 2010;13(2):31-7. [Persian]

20- Novara G, Ficarra V, Boscolo-Berto R, Secco S, Cavalleri $\mathrm{S}$, Artibani W. Tension-free midurethral slings in the treatmentoffemalestressurinaryincontinence:a systematic review and meta-analysis of randomized controlled trials of effectiveness.EurUrol. 2007;52(3):663-78.

21- Curts L. Mobys dictionary of medicine, nursing and health professios. $7^{\text {th }}$ Edition. St. Louis: Mosby Elsevier; 2006. p. 1705.

22- Mohammadi K, Heidari M, Faghihzadeh S. The female sexual function index (FSFI): validation of the Iranian verion. Payesh. 2008;7(3):269-78. [Persian]

23- Momeni Movahed Z, Pakgohar M, Montazeri A. Pelvic organ Prolapse/Urinary Incontinence sexual Questionnaire (PISQ-12): psychometric validation of the Iranian. Int Urogynecol J. 2015;26(3):433-9.

24- Rust J, Derogatis L, Rodenberg C, koochaki P, Schmitt S, Golombok S. Development and validation of a new screening tool for hypoactive sexual desire disorder: the brief profile of female sexual function (B-PFSF). Gynecol Endocrinol. 2007;23(11):638-44.

25- Tuncer M, Tarhan F, Kafkasli A, Demir K, Yucetas U, Faydaci G, et al. The effects of stress incontinence surgery on sexual function and life quality of women. Arch Ital Urol Androl. 2016;88(2):106-10.

26- Brubaker L, Chiang S, Zyczynski H, Norton P, Kalinoski DL, Stoddard A, et al. The impact of stress incontinence surgery on female sexual function. Am J Obstet Gynecol. 2009;200(5):562.e1-7.

27- Pauls RN, Silva WA, Rooney CM, Siddighi S, Kleeman SD, Dryfhout V, Karram MM. Sexual function after vaginal surgery for pelvic organ prolapse and urinary incontinence. Am J Obstet Gynecol. 2007;197(6):622.e1-7.

28- Azar M, Noohi S, Radfar S, Radfar MH. Sexual function in women after surgery for pelvic organ prolapse. Int Urogynecol J Pelvic Floor Dysfunct. 2008;19(1):53-7.

29- Handa VL, Cundiff G, Chang HH, Helzlsouer KJ. Female sexual funection and pelvic floor disorders. Obstet Gynecol. 2008;111(5):1045-52.

30- Kariman NS, Tarverdi M, Azar M, Alavi Majd H. Evaluating the effects of colporrhaphy on the sexual satisfaction of women. J Reprod Infertil. 2005;6(3):254-60. [Persian]

31- Pace G, Vicentini C. Female sexual function evaluation of the tension-free vaginal tape (TVT) and transobtraturator suburethral tape (TOT) incontinence surgery: results of a prospective study. J Sex Med. 2008;5(2):387-93.

32- Abu Ali RM, Al Hajeri RM, Khader YS, Ajlouni KM. Factors associated with sexual dysfunction in Jordanian women and their sexual attitudes. Ann Saudi Med. 2009;29(4):270-4.

33- Rogers RG, Coates KW, Kammerer-Doak, D, Khalsa S, Qualls C. A short form of the pelvic organ prolapse/Urinary Incontinence Sexual Questionnaires (PISQ-12). Int Urogynecol J Pelvic Floor Dysfunct. 2003;14(3):164-8.

34- Kammerer Doak D. Assessment of sexual function in women with pelvic floor dysfunction. Int Urogynecol J Pelvic Floor Dysfunct. 2009;20 (Suppl 1):S45-50. 